\title{
Transferrin Receptor-Targeted Liposomal p53 cDNA
}

National Cancer Institute

\section{Source}

National Cancer Institute. Transferrin Receptor-Targeted Liposomal p53 CDNA. NCI

Thesaurus. Code C29474.

A cationic liposomal, tumor-targeting p53 (TP53) gene delivery system with potential anti-tumor activity. Transferrin receptor-targ eted liposomal p53 cDNA contains plasmid DNA encoding the tumor suppressor protein p53 packaged in membrane-like liposome capsules that are complexed with anti-transferrin receptor single-chain antibody ( $T f R s c F v)$. Upon systemic administration, the anti-TfRscFv selectively binds to tumor cells expressing transferrin receptors. The p53 plasmid is delivered into the nucleus and as a result, p53 protein is produced in tumor cells that have altered p53 function. This results in the restoration of normal cell growth control mechanisms as well as normal response mechanisms to DNA damage. 